diplenyl-iodonium hydroxide and silver iodate are produced, in accordance with the following equation:-

$$
\mathrm{C}_{6} \mathrm{H}_{5} \cdot \mathrm{IO}+\mathrm{C}_{6} \mathrm{H}_{5} \cdot \mathrm{IO}_{2}+\mathrm{AgOH}=\mathrm{AgIO}+\mathrm{HO} \cdot \mathrm{I}\left(\mathrm{C}_{6} \mathrm{H}_{5}\right)_{2} \text {. }
$$

When a mixture of the two iodine aromatic derivatives, in the proportions required hy the above equation, together with sufficient oxide of silver, is vigorously agitated for three hours in a triturating machine, such as that in use in the Heidelberg laboratory, and filtered, the clear solution upon the addition of potassium iodide solution yields over ninety per cent. of the calculated weight of crystals of diphenyl iodonium iodide. The iodic acid remains partly as silver salt in the residue, and partly as iodate of the new base in the solution.

The salis of the iodonium bases bear a remarkable resem. biance to those of lead, silver, and in particular thallium. Those ( $f$ the first discovered base were describet? last week, but those of the diphenyl base are still more interesting, and many of them crystallise well.

The jodide obtained as above descrihed forms large and heaut $\mathrm{i}$ fuliy grouped acicular crystals which melt at $175^{\circ}-176^{\circ}$. During the act of melting it passes completely into mono-iodo-benzene, of which it is a polymer :-

$$
\text { I. I }\left(\mathrm{C}_{6} \mathrm{H}_{5}\right)_{2}=\mathbf{2} \mathrm{C}_{6} \mathrm{H}_{5} \mathrm{I} \text {. }
$$

The chloride, $\mathrm{Cl}$. $\mathrm{I}\left(\mathrm{C}_{6} \mathrm{H}_{5}\right)_{2}$, is slowly precipitated upon the addition of a soluble chloride to the aqueous solution of the free base, in crystals which are very similar in aspect to those of lead chloride. From hot aqueous solutions excellent crystals separate upon cociling.

The bromide, $\mathrm{Br}$. I $\left(\mathrm{C}_{6} \mathrm{H}_{5}\right)_{6}$, crystallises likewise from hot water, and the crystals are perfectly colourless, and frequently attain large size.

The aqueous solution of the free base, HO.I $\left(\mathrm{C}_{6} \mathrm{H}_{5}\right)_{2}$, is very stable; it may he preserved unchanged for many days. Upon concentration of the strongly alkaline solution a thick syrup is eventually obtained of powerfully alkaline nature, but which has not yet been crysiallised. It absorbs carbon dioxide with great avidity, forming a carbonate of the base, which effervesces upon the additi: $n$ of a dilute acid; the carbonate, indeed, very much resembles that of thallium, being soluble in water.

Strangest of all these reactions, pes haps, is the behaviour of the solution of the base towards soluble sulphides. Sodium sulphide precipitates a bright yellow sulphide of the hase, clostly resembling arseniot: sulphide, while ammonium sulphide precipitates a beautiful deep orange-coloured polysulphide, identical in appearance $w$ ith freshly precipitated antimonious sulphide. Both sul. phide and polysulphide decompose after a time with separation of an oil, consisting in the former case of iodobenzene and phenyl sulphide, and in the latler case of the same substances together with ol her phenyl sulphides. The work is being continued, and Prof. Meyer bopes before long to have something further to communicate concerning this unexpected and exceptionally interesting class of compounds. A. E. Tutron.

\section{THE ETHNOGRAPHY OF THE ARAN ISLANDS, COUNTY GALHAY.}

WIIEN Professors Cunningham and Haddon opened their anthropometric laboratory in Lublin, rather more than two years ago, one of their objects was to promote systematic research in the country districts of Ireland. We have now received the first-fruits of the laboratory in the form of a paper on the ethnography of the Aran lslands, by Prof. A. C. Haddon and Dr. C. R. Browne, read before the Royal Irish Academy. The lines of research originally proposed have been considerably exceeded, and the paper before us is in reality a brief monograph of the islands. The observations, however, have been made chiefly on the inhabitants of Aranmore, the northern and laigest of the three islands forming the group ; and the southern island, Inisheer, was not visited at all.

The inhabitants of Inisheer, and of the middle island (Inish maan), have been less subject to foreign influence than Aranmore, but the proximity of Inisheer to the mainland having rendered intercourse with Ireland easy, aprears to have given to the inhabitants of that island a somewhat distinctive character.

The number of individuals actually measured by the authors was twenty-seven, twenty of them being natives of Aranmore, and the other seven being Inishmaan men; all were males.

No. I 272 , vor.. 49]
The general physical characters of the people are thus described :-

Height.-The men are mostly of a slight but athletic build; and though tall men are occasionally to be met with among them, they are, as a rule, considerably below the average Irish stature. The Aran average is $1645 \mathrm{~mm}$, or about 5 feet $4^{\frac{3}{4}}$ inches; that of 277 Irishmen is $1740 \mathrm{~mm}$., or 5 feet $8 \frac{1}{2}$ inches.

Limbs. - The span is less than the stature in a quarter of the cases measured, a rather unusual feature in adult males. The hands are rather small, but the forearm is often unusually long.

Head:- The head is well shapen, rather long and narrow, but viewed from above, the sides are not parallel, there being a slight parietal bulging.

The mean cephalic index, when reduced to the cranial standard, is $75^{\circ} \mathrm{I}$, consequently the average head is, to a slight extent, mesaticephalic ; although, as a matter of fact, the num. ber measured is nearly evenly divided hetween mesaticephalic and dolichocephalic. The top of the head is well vaulted, so that the height above the ears is considerable.

The forehead is broad, upright, and very rarely receding; not very high in most cases. The superciliary ridges are not prominent.

Face.-The face is long and oval, with well-marked features. The eyes are rather small, close logether; they are marked at the outer corners by transverse u rinkles. The irises are in the great majority of cases blue or blue-grey in colour. The nose is sbarp, narrow at the base, and slightly sinuous or aquiline in profile. The lower lip is, in many cases, rather large and full. The chin is well developed. The cheek-bones are not prominent. In quite a large proportion of cases, the ears, though not large, stand well out from the head. In many men the length between the nose and the chin has the appearance of being decidedly great. The complexion is clear and ruddy, and but seldom freckled. On the whole; the people are decidedly good-looking.

Hair. - The hair is brow $\mathrm{n}$ in colour, in most cases of a light shade, and accompanied by a light and often reddish beard. As a rule, the hair on the face is moderately well developed.

Sight and Hearing. - The sight and hearing of the people are, as a rule, exceedingly keen, especially the former. The range atd distinctness of the vision is astonishing, as we have had occasion to know; and we are informed by Dr. Kean that, on a clear day, any of the men whose eyesight is average can, with the naked eye, make out a small sailing boat at Black Head, twenty miles away, before he can see it with a good binocular.

The observations of the authors tend to show that the natives of Inishmaan are rather lighter than the Aranmore men.

The population is decreasing, but as the number of births is considerably in excess of the deaths, the decrease must be attributed to emigration. That some of the inhabitants live to a very advanced age is evidenced by the fact that a tombstone in Killeany records the death of a man in the I I gth year of his age.

The islanders appear to be exceptionally honest, straightforward and upright in their dealings, and illegitimacy is almost unknown.

They are singularly non-musical, there being no piper, fiddler, or musician of any sort on the islands.

The majority of the people can understand and speak English, but lrish is the language most generally spoken among themselves.

Almost all the marriages take place immediately before Lent. There is no courting or love-making, but the young man who has decided to marry goes to the house where there is a suitable girl, and asks her to marry him; a man has been known to ask ihree girls in the same evening before he was accepted.

Wakes are held even upon those who die abroad. Occasion. ally a funeral procession stops on the road to the cemetery at certain spots, and the mourners raise small memorial heaps of stones; in Aranmore there are about two dozen of these roadside monuments; but the practice does not seem to date back beyond the beginning of the last century, and appears to have died out within the last twenty years.

The Aranites believe in fairies, banshees, and ghosts; and a corpse is always carried out of a house through the back door.

It is said that if anyone at a marriage repeats the benediction after the priest, and ties a knot on a piece of string at the men. tion of each of the three sacred names, that marriage will be childless for fifteen years, or until the knotted string has been burnt. 
Pin-wells and rag-bushes are still frequented, and on the night before emigrating people will sleep in the open, beside one of the holy wells, in order that they may have good f rtune in the country to which they are going. There is a firm belief in the power of the Evil Eye, and on certain days that are considered unlucky, even burials are avoided.

The antiquities of the Aran Islands are numerous and varied, but have never yet been systematically described; and the authors urge upon the Irish Academy the desirability of its undertaking a detailed survey of them.

No opinion is expressed as to what race or races the Aranites belong, but it is argued that they cannot be Firbolgs, if the latter are correctly described as "small, dark-haired, and swarthy."

A short bibliography is given at the end of the paper, and a few photographs, taken by Prof. Haddon, give a general idea of the appearance of the people.

\section{ELECTRICAL SANITATION.}

A PRACTICAL application of electricity to sanitation has recently been made. Two systems have been tested upon a very considerable scale, in both of which the electrolytic action of the current has been utilised.

The two methods at present before the public are Mr. William Wehster's, which is being carried out by the Electrical Purifi. cation Association (Limited), and that ascribed to Mr. Eugene I [ermite, and worked by him in conjunction with Messrs. Paterson and Cooper.

As has occurred so frequently before, both these inventors appear to have conceived the same idea about the same time. Each of them took out three patents in the year 1887 , but though each had the same object in view, and although in their early patents they seemed almost to be running on the same rather than on parallel lines, their recent practice is quite distinct.

Mr. Webster treats the sewage directly. He places parallel iron electrodes within a conduit or shoot, through which the sewage is passed, the electrodes being alternately connected with the positive and negative poles of a dynamo. The nascent ammonia thus evolved at the negative electrode'produces an alkaline reacti $\backsim$, which effects the precipitation of the solid suspended matter, while at the positive pole nascent oxygen and chlorine are evolved, producing an acid reaction, whereby the organic impurities held in suspension or solution are readily decomposed and purified.

This system has been tested on a large scale, both at Cross ness and at Salford. The amount of sludge formed is said to be smaller than in any precipitation process, anil the effluent so pure as not to require further treatment by filtration. The process has been reported on in the most favourable manner, as regards the chemical tests of the effluent, and the ease and uniformity with which the results are obtained.

Mr. Hermite's system consists in the treatment of sea water or other chloride solutions by electrolysis. The water thus electrolysed in reservoirs is conducted as a disinfecting liquid by suitable pipes to places requiring disinfection, where it is stored in cisterns and used in place of ordinary water. The system has been experimentally tested at Havre, Lorient, Brest, and Nice, and has been reported upon most favourably in every case. It is now being tried at Worthing, where an installation has been set up under the auspices of the Mayor and corporation. As in the previous system, an oxygenated com. pound of chlorine is held to be produced, which burns up the sewage matter, and absolutely destroys all microbes.

Several questions have to be considered from a scientific and practical point of view, in connection with both these inven tions, before their general application can be effected. The scien tific view of the subject, after all, resolves itself into the answer to a single question: Is the process quite trustworthy to remove the maximum of organic malter from the sewage, and thoroughly sterilise it? As regards the practical point of view, the removal and utilisation of the sludge will have to be faced, in the first process $r$ ferred to; whilst in the second, in which sludge is said not to be produced, a second water supply to houses, and the chemical action of this disinfecting water upon the pipes, tubes, and reservoirs through which it has to pass, will have to be very fully considered befo:e the system can be adopted.

N O. I 272 , VOL. 49]

\section{ON HOMOGENEOUS DIVISION OF SPACE. ${ }^{1}$}

\section{II.}

§ Io. NOW, suppose any one pair of the tetrahedrons to be taken away from their positions in the primitive paral. lelepiped, and, by purely translational motion, to be brought into position with their edges of length QD coincident, and the same to be dune for each of the other two pairs. The sum of the six angles at the coincident edges being two right angles, the plane laces at the common edge will fit together, and the condition of parallelism in the motion of each pairfixes the order in which the three pairs come together in the new position, and shows us that in this position the three pairs form a parallelepiped essentially different from the primitive parallelepiped, pruvided that, for simplicity in our present considerations, we suppose each tetrahedron to be wholly sialene, that is to say, the seven lengths found amongst the ejges to be all unequal. Next shift the tetrahedrons to bring the edges $Q E$ into coincidence, and next again to bring the edges $\mathrm{QF}$ into coincidence. Thus, including the primitive parallelepiped, we can make four different parallelepipeds in each of which six of the $t=$ trabedrons have a common edye.

$\S \mathrm{Ir}$. Now take the two pairs of tetrahedrons having edges of length equal to $\mathrm{QA}$, and put them together with these edges coincider $t$ Thus we have a scalene octahedron. The remain. ing pair of tetrahedrons placed on a pair of its parallel faces complete a parallelepiped. Similarly two other parallelepipeds may be made by putting together the pairs that have edgre; of lengths equal to $\mathrm{QB}$ and $\mathrm{QC}$ respectively with those edges coincident, and finishing in each case with the remaining pair of tetrahedrons. The three parallelepipeds thus found are essentialiy different from one ancther, and from the four of $\S \mathrm{IO}$; and thus we have the seven parallelepipeds fulfilling the statement of $\S 9$. Each of the seven parallelepıpeds corresponds to one and the same homogeneous distribution of points.

$\S \mathrm{r}$ 2. Going back to $\S 4$, we see that, by the rule there given, we find four different ways of passing to the tetrakaidekahedron from any one chosen parallelepiped of a homogeneous assem. blage. The four different cellular systems thus found involve four different sets of seven pairs of neighbours for each point. In esch of these there are four pairs of neighbours in rows parallel to the three quartets of edges of the parallelepiped and to the chosen body-diagonal; and the other three pairs of neighbours are in three rows parallel to the face-diagonals which meet in the chosen body-diagonal. The second (\$II) of the two modes of putting torether tetrahedrons to form a parallelepiped which we have been considering suggests a second mode of dividing our primitive parallelepiped, in which we should first truncate two opposite corners and then divide the octahedron which is left, by two planes through one or other of its three diagonals. The six tetrahedrons obtained by any one of the twelve ways of effecting this second mode of division give, by their twenty-four corners, the twenty-four corners of a spacefilling tetrakaidekaliedronal cell, by which our fundamental problem is solved. But every solution thus obtainable is clearly obtainable by the simpler rule of $\$ 4$, commencing with some one of the infinite number of primitive parallelepipeds which we may take as representative of any homogeneous distribution of points.

$\S \mathrm{r}$ 3. The communication is illustrated by a model showing the six tetrahedrons derived by the rule 4 from a symmetrical kind of primitive parallelepiped, being a rhombohedron of which the axial-diagonal is equal in length to each of the edges. The homogene,us distribution of points corresponding to this form of parallelepiped is the well known one in which every point is surrounded by eight others at the corners of a cube of which it is the centre; or, if we like to look at it so, two simple cubical distributions of single points, each point of one distri. bution being at the centre ot a cube of points of the other. To understand the tactics of the single homogeneous ass mmblage constituted by these two cubic assemblages, let $\mathrm{P}$ be a point of one of the cubic assemblages, and $Q$ any one of its four nearest neighbours of the other assemblage. $Q$ is at the centre of a cube of which $\mathrm{P}$ is at one corner. Let $\mathrm{PD}, \mathrm{PE}, \mathrm{PF}$ be three conterminous edges of this cube so that A, B, C are points of the first assem 'age nearest to $P$. Again $Q$ is a corner of a cube of which $\mathrm{P} \mathrm{i}$, he centre; and if $\mathrm{QA}, \mathrm{QB}, \mathrm{QC}$ are three conterminous edges of this cube, D, E, F are points of the second assemblage

1 A paner read bef.re the Roval Society on January 18 , by Lord Kelvin, P.R.S. (Cuntinued from $p .44^{8 .)}$ 